\title{
Attracting primary school children to mathematics: The case of a city mathematical marathon
}

\author{
Mark Applebaum ${ }^{1}$ and Viktor Freiman ${ }^{2}$ \\ ${ }^{1}$ Kaye Academic College of Education, Beer-Sheva, Israel \\ ${ }^{2}$ University of Moncton, Canada \\ For correspondence: mark@kaye.ac.il
}

\begin{abstract}
:
In this paper we report on the first year of an online competition in which 480 students took part. After a brief presentation of the organizational structure of the marathon and general data about students' participation, we discuss findings from questionnaires about participants' attitudes towards mathematics, technology, and their perception of the experience. We focus on the two following questions:

(1) How can more students be attracted to mathematics by means of competitions?

(2) How do students perceive their participations in such events?

In addition, we analyse several examples of challenging tasks solved by participants and their contributions to the online Discussion Forum. Our data does provide us with better insight into how this experience extends mathematics learning beyond the classroom by means of informal opportunities, such as competitions.
\end{abstract}

Keywords: challenging mathematics, competitions, solving problems, out of school activity

\section{Context and problem statement}

How can we foster the genuine interest many students have in mathematics through activities beyond the formal academic settings? Competitions are known as potentially rich opportunities for attracting young learners by proposing unusual non routine problems thus creating more opportunities for challenge they need and like. By discussing the role of mathematics competitions in nurturing students' interest in mathematics, Kenderov (2006) emphasised their value in identifying, motivating, and developing young talent, steering it towards careers in science, while engaging millions of students and educators.

According to Kenderov (2006), the multifaceted impact of holding mathematics competitions ranges from the preservation and maintenance of mathematical heritage to 'providing a constant stimulus for improvement of school systems around the world' (p. 1597). Moreover, it is important to complement traditional forms of competitions with more inclusive and less known events through a 'stronger consolidation and collaboration of teachers, schools, universities, and educational authorities' (ibid.).While existing literature focuses mostly on reporting about mathematics competitions oriented toward talented students (Soifer, 2010, 2012; Rosolini, 2011),our aim was to describe an experience of organising a mathematical contest open to all Grade 5 students in one city (about 2000 students in total) with close to 200,000 inhabitants. In fact, by working collaboratively with schools, communities and local authorities, we succeeded in uniting forces of several key educational partners and in using the potential of online environments to create a mechanism that makes it possible for everyone to participate.

Mathematical competitions have a rich history, and have been organised in different forms, indifferent venues and for different types of students. As a part of challenging mathematical activities beyond the 
classroom, the model of the City Mathematical Marathon (CMM) allows all interested students to explore new opportunities of doing mathematics other than academic activities in a regular classroom. As such, this experience may help them to apply skills they have already acquired to new situations and, at the same time, enrich their learning experience (Kenderov et al., 2009).

The authors have been exploring the challenging potential of mathematical competitions, ranging from the face-to-face forms to virtual ones, since 2009. Our first observations seem to confirm a potential of competitions and contests to help to extend challenge beyond the classroom while nurturing mathematical promise and developing a taste for mathematics (Taylor and Barbeau, 2009; Freiman and Applebaum, 2011). This article continues our reflection on the role of competitions in popularising mathematics among a larger group of students in a form which combines competitive and educational factors, alike, according to Berzina, Bonka and Lace, quoted in Koichu and Andzans (2009), they 'have a vital effect on students' attitudes toward mathematics and on their problemsolving skills' (p. 299).

The CMM was organised in three stages over the course of one school year. The first stage was preparatory: bringing together all planning partners, developing the marathon's structure and content, and informing potential participants in local schools. The second stage was a 12-week long online competition in which 480 students took part. After that, 50 participants with the highest scores were invited to go on to the third stage, which consisted of a face-to-face contest, a workshop with an invited lecturer and distribution of prizes.

In the next sections we describe a case study in which we collected and analysed data from the first year of competition, focusing only on its online part. Drawing on the description of the competition and students' participation, as well as results from questionnaires regarding participants' attitudes towards mathematics, technology, and their perception of the overall experience, we intended to investigate the two following questions:

(1) How can more students be attracted to mathematics by means of competitions?

(2) How do students perceive their participation in such events?

In addition, we give several examples of challenging tasks solved by participants and their contributions to the online Discussion Forum that helped us gain more insight into how students use informal opportunities of doing more mathematics beyond the classroom.

\section{Theoretical background}

The popularisation of mathematics has a long tradition but only relatively recent impetus for systematic scrutiny. There are several issues to consider as we improve our practice by developing effective programs to help a broad, general population to acquire a fruitful appreciation and facility for mathematics (Schneider, 1994). According to de Guzman (1990), popularisation means sharing mathematics, its beauty and its power with a wider public; trying to change the attitudes toward mathematics of many who are in need of such a change; encouraging people to be more active mathematically by persuading them that this can lead them towards a more pleasurable and intellectually fuller life, and finally, developing mathematical activity in an atmosphere of freedom, not of coercion, and trying to get away from the odious feeling about mathematics that so many children and adults share. Moreover, a study conducted by Simpkins et al. (2006) found a link between participation of young students, as early as Grade 5, in informal after-school mathematics and science activities and further development of their self-confidence and interest; and that this link can affect their choice to continue studying these subjects in high school and beyond. 
Among different types of activities that help in the popularisation of mathematics, competitions play an important role, as they can be great fun and rewarding for those who take part in them. According to ICMI (1990), thanks to children's natural tendency to compete, mathematical competitions have a strong motivational power. The authors mention that a wide variety of competitions should be created to cover different age groups and different types of children's interests (problem solving/projects, multiple-choice/essay type, team/individual, relay, etc.) so that each pupil can choose the competition attuned to his/her character and personality. Examples, given in ICMI (1990) from the USA and France, show that there is a large general audience for competitions, even at the elementary level. Also, Regato (1982) analyzes the structure of a 'Math Games Tournament' - a mathematics contest which makes use of educational games. The major goal of a mathematics games tournament should be to bring parents, teachers, administrators, and students together in a social event that prompts the development of mathematical concepts and skills. This model inspired us in the construction of our CMM model.

\section{Description of the City Mathematical Marathon (CMM)}

\section{Structure of the competition}

Bringing together mathematicians, mathematics educators, and headmasters to organise and conduct a mathematical competition at the local level is a complex and challenging task. At the first stage of our project an intention to collaborate was declared by the local branch of the Ministry of Education, the local municipality and the Academic College of Education. The joint team included inspectors of mathematics, inspectors of primary schools, researchers, and pre-service teachers. In order to determine the structure of the marathon, several decisions were made collectively regarding the age of the students, number of weeks, number of problems to be given each week, how to work with school teachers, the content and the structure of the website, and other organisational aspects.

The choice to include only students from the 5 th grade in the competition was made by inspectors from the local branch of the Ministry of Education. The choice of this grade level was first made to focus on primary school (Grades 1-6), rather than on secondary school, in order to attract younger students to mathematics as early as possible. Another consideration was including students knowledgeable in the use of the Internet with a certain degree of autonomy. From the logistical perspective the choice between Grades 5 and 6 took into account the fact that for Grade 6 students this was a busy time of the year, as they had to complete all their primary school academic requirements. Another factor considered was the need for the students to have acquired some critical mass of mathematical content in the regular school curriculum (topics, facts, concepts, operations; by Grade 5 the students had already learnt whole numbers, fractions and problem solving) to make a greater variety of interesting mathematical problems.

Following these decisions, the competition was conducted in two rounds, one in the form of an online open-to-all competition (12 week - rounds). All Grade 5 children who attended a public school in the chosen city were eligible to participate; the only requirement was to have a computer with Internet access, so they could work from home or from school. The "virtual round "was followed by a face-toface contest among the top 50 participants who had attained the highest scores. In the end, prizes were awarded to the winners. Before the start of the competition, an information session had been organised for the teachers at the academic college. Interested mathematics teachers from 27 of the 38 schools of the region participated in this meeting (one teacher per school; schools that did not send a representatives were informed later by their school inspectors). The teachers' main mission after this meeting was to inform their students about the competition and encourage them to participate.

During the online stage, every Sunday for a period of 12 consecutive weeks, 4 new problems according to four levels of difficulty were posted on the website, offering students a multiple choice of 
possible answers; the correctness of the answer was checked automatically by the computer system and total scores were adjusted accordingly. Each problem was scored with 0 points (wrong answer) or 5 points (correct answer). A week after the end of each set, detailed solutions, adapted to the level of understanding of Grade 5 students, were prepared by 3 pre-service teachers and published on the CMM website. Teachers could follow the competition by monitoring their students' results and encouraging them to participate. The teachers, however, were asked not to solve problems during the week that the problem was active and open on the site; however, they were permitted to give some hints if their students asked them. Another recommendation given to the teachers was to integrate the published solutions of the previous weeks' sets into their class discussions whenever possible, so as to ensure the formative character of the experience.

Creating challenging problems

Challenging problems were created by pre-service teachers according to the following two types: (a) problems with a context that appeals to common sense and logic, inquiry-based problems and nonstandard problems that are not part of learning tasks used in a regular classroom, and (b) word problems similar to those that appear in 5thgrade textbooks. In all, about $75 \%$ of the problems belong to category (a) and the remaining $25 \%$ belong to category (b).

After approval by tutors and modifications made in some items, if deemed necessary, a number of distracters (possible answers) were introduced using a multiple-choice scale, followed by the second round of discussion between tutors and pre-service teachers regarding the distracters' validity. The final version of the tasks was presented to one in-service teacher who was asked to check whether the tasks were appropriate for 11-12 year-old students. The next step was proofreading of the texts of each problem by a language expert. Finally, all 48 problems were divided into12 sets (4 problems per set) according to the level of difficulty ( 2 not so difficult and 2 more difficult).Then, all the sets were checked again and improved by tutors and classroom teachers.

Virtual environment

In order to support the online part of our competition, similarly to our previous projects (See http://www8.umoncton.ca/umcm-mmv/index.php, the Virtual Mathematical Marathon), a new website was created by using a Moodle platform, onto which 12 sets of 4 problems were uploaded and presented to the students on a weekly basis. Solutions of the sets were published a week later along with the names and scores of the 50 leading participants. Additionally, in this way every student could find out his/her own total score and personal success on every single problem.

As new features, we established two electronic discussion forums allowing participants to ask questions. One forum was open to the teachers and the second one to the participating children. Surprisingly, no teacher used the forum to ask for help. At the same time, the forum for children was very actively used. There were some moments when pre-service teachers were not available online and it was children that answered the questions asked by their peers. To provide the organisers with the participants' statistics, the system could check at what exact time the participants opened the tasks on the website, uploaded their solutions and questions for the forum, or just simply navigated on the website.

There were some other functions available on the website as well, such as an information desk, technical support, and online questionnaires introduced by researchers at the beginning, and at the end, of the marathon which we are going to analyse in the following section. 


\section{Data on students' participation and perceptions of the virtual round}

General statistics

The number of students varied from one set to the next; the competition drew 480 students out of nearly 2,000 of the total number of Grade 5 students in the region, which is a sign of active participation. Our data show that some students were using the website in the after-school hours, from as early as 6:25 pm and as late as 00:10 am. The participation was also sustained over the holidays. The following table shows participants' general statistics (Table 1):

Table 1. General data about participation

\begin{tabular}{|l|l|l|l|l|l|l|l|l|l|l|l|l|}
\hline Round & 1 & 2 & 3 & 4 & 5 & 6 & 7 & 8 & 9 & 10 & 11 & 12 \\
\hline Number of students who answered & 373 & 257 & 193 & 117 & 141 & 96 & 88 & 72 & 75 & 71 & 58 & 58 \\
\hline $\begin{array}{l}\text { Number of students who consulted } \\
\text { posted solutions }\end{array}$ & 88 & 69 & 74 & 80 & 31 & 38 & 37 & 41 & 36 & 25 & 25 & 30 \\
\hline $\begin{array}{l}\text { Number of time students who opened } \\
\text { posted solutions }\end{array}$ & 168 & 120 & 162 & 168 & 56 & 84 & 68 & 78 & 54 & 36 & 38 & 64 \\
\hline
\end{tabular}

From the table, we see that the number of the students who participated at the virtual stage of the competition varied between 58 (in the 11thand 12throunds) and 373 (in the 1stround), a dynamic we also observed in our previous projects on the marathon, in which many students started the competition, but fewer exhibited the perseverance to stay till the end.

The number of students that consulted the published solutions prepared by pre-service teachers varied from a low $22 \%$ (in the 5thround) to a high $68 \%$ (in the 4 thround). In the last three rounds, towards the end of the virtual stage of the competition, the number of students (in percentages) that viewed the published solutions constantly increased: 35\%- 43\%-52\% accordingly.

When students wished to view the solutions, they could open a PDF file displaying all four solutions for each set. The average number of opened solutions per student was 1.91, which means that many students that opened published solutions once, came back and opened the same set of solutions one more time, at least.

In this paper, we also present results of two online questionnaires, some examples of tasks and results achieved by students, as well as an example of communication in the forum for children.

Data from questionnaires

In order to investigate students' attitude towards mathematics and technology, an online questionnaire (given twice: at the beginning and at the end of the marathon) was used. It contained two sections: one on students' attitude towards mathematics and the other on their attitude towards technology. 235 (out of 480) students responded. The participants who continued solving problems till the end of the marathon were asked for their perceptions of the overall experience with the CMM. 51 students who remained in the competition (47 of whom were invited to the face-to-face round) answered this questionnaire, also online.

For each item, on both questionnaires, there was a choice of answers according to a Likert scale (1-4), where 1 meant completely disagree, 2 -partly disagree, 3 -partly agree and 4 - completely agree. The following table summarises data (mean and standard deviation) from the first questionnaire (Table 2). 
Table 2. Data from the students' questionnaires (beginning of competition), N=235

\begin{tabular}{|l|l|l|l|}
\hline $\mathrm{N}$ & Question & Mean & St. D \\
\hline 1 & I enjoy Math class. & 3.30 & 0.92 \\
\hline 2 & I'm successful in Math. & 3.32 & 0.80 \\
\hline 3 & I like to solve Math problems. & 3.27 & 0.91 \\
\hline 4 & I'm interested in Math. & 3.36 & 0.89 \\
\hline 5 & I always do my homework in Math. & 3.49 & 0.82 \\
\hline 6 & My success in Math depends only on my own effort. & 3.36 & 1.04 \\
\hline 7 & I'm active in Math class. & 3.52 & 0.81 \\
\hline 8 & I help other students in Math class. & 2.87 & 1.05 \\
\hline 9 & If I make an effort I'll be successful in Math. & 3.57 & 0.86 \\
\hline 10 & I have a fear of Math tests. & 1.56 & 0.93 \\
\hline 11 & I have a fear of Math. & 1.27 & 0.77 \\
\hline 12 & I have difficulties with Math. & 1.76 & 1.02 \\
\hline 13 & Even if I make an effort I will not get high grades in Math. & 1.32 & 0.81 \\
\hline 14 & I'm one of the first kids in class to get new internet games and applications. & 2.45 & 1.11 \\
\hline 15 & When I'm on the Internet, the time passes quickly and I'm not tired. & 2.68 & 1.19 \\
\hline 16 & When I'm in school, I can't wait to go back home to my PC. & 2.38 & 1.12 \\
\hline 17 & All of my free time I'm on the Internet. & 2.56 & 1.12 \\
\hline 18 & I help my friends when they have problems with the Internet. & 2.62 & 1.17 \\
\hline
\end{tabular}

Regarding their attitude towards mathematics, our data indicate that most of the participants tend to affirm their interest in mathematics $(\mathrm{M}=3.36, \mathrm{SD}=0.89, \mathrm{~N}=235)$. However, a small group of students (36) stated that they are not really that interested in mathematics, but decided to participate in the CMM, nonetheless.

It is true that although most students participating in the CMM responded that they like solving mathematical tasks $(\mathrm{M}=3.27, \mathrm{SD}=0.91, \mathrm{~N}=235)$, there were still 46 students that disagreed with the statement: "I like solving math tasks".

In their relation to formal schooling, they also seem to enjoy math lessons $(M=3.30, S D=0.92, N=235)$, are active in math class $(\mathrm{M}=3.52, \mathrm{SD}=0.81, \mathrm{~N}=235)$, always do their homework $(\mathrm{M}=3.49, \mathrm{SD}=0.82$, $\mathrm{N}=235)$, make an effort to succeed in mathematics ( $\mathrm{M}=3.57, \mathrm{SD}=0.86, \mathrm{~N}=235)$, all of which seems to lead to good results $(\mathrm{M}=3.32, \mathrm{SD}=0.80, \mathrm{~N}=235)$. Again, it is interesting to see that though a small group of students seem to disagree with these statements they still remain involved in this non-compulsory experience.

The internal validity of these opinions seems to be confirmed by data showing a lower rate of agreement on all four items that examine negative attitudes. Namely, participants state that they fear neither mathematics $(\mathrm{M}=1.27, \mathrm{SD}=0.77, \mathrm{~N}=235)$ nor math tests $(\mathrm{M}=1.56, \mathrm{SD}=0.93, \mathrm{~N}=235)$. Most of them deny having difficulties in mathematics $(\mathrm{M}=1.76, \mathrm{SD}=1.02, \mathrm{~N}=235)$ and deny the feeling that their efforts do not lead to success ( $\mathrm{M}=1.32, \mathrm{SD}=0.81, \mathrm{~N}=235)$.

The only item of this part of the questionnaire that indicates rather divided opinions is the one regarding helping other students $(\mathrm{M}=2.87, \mathrm{SD}=1.02, \mathrm{~N}=235)$.

The items related to attitudes towards the Internet also show rather divided opinions. In fact, there seems to be no agreement among participants regarding spending all their time on the internet $(\mathrm{M}=2.56, \mathrm{SD}=1.12, \mathrm{~N}=235)$, getting new games and applications $(\mathrm{M}=2.45, \mathrm{SD}=1.11, \mathrm{~N}=235)$, having a 
feeling of time "flying" when online $(\mathrm{M}=2.68, \mathrm{SD}=1.19, \mathrm{~N}=235)$, and having the desire to go back to their computer after school $(\mathrm{M}=2.38, \mathrm{SD}=1.12, \mathrm{~N}=235)$. Similar to the help in mathematics, opinions were also divided with regard to helping their peers with Internet problems $(\mathrm{M}=2.62, \mathrm{SD}=1.17, \mathrm{~N}=235)$. The results displayed in the table featuring attitudes towards mathematics show that already in the beginning, scores were extremely high in terms of motivation and attitude by most of the 235 participants who answered the first questionnaires; this finding shows that we have actually at least 200 children in the classrooms, out of a total of 2000 (the number of 5thgrade students in the city schools) who seem to like mathematics, are successful learners and enjoy solving difficult problems. Using the notion of mathematical promise $(20 \%-25 \%$ of the whole student population) introduced by the NCTM Task Force (Sheffield, 1999), we can suggest that at least part of the participants who deliberately took part in our out-of-school event belong to such a category. Also, according to Leikin's model of mathematical promise (Leikin, 2009) abilities, motivation, and beliefs can be developed and transformed if the opportunities provided to students match their potential (p. 388).

In fact, at the end of the competition, 51 students who remained till the end of the online stage answered our second questionnaire (47 of them were successful at this stage and, thus, were invited to the face-to-face round) about their evaluation of the experience (Table 3).

Table 3. Data from the students' questionnaire (end of competition), $\mathrm{N}=51$

\begin{tabular}{|l|l|l|l|}
\hline $\mathrm{N}$ & Item & Mean & St. D \\
\hline 19 & I enjoyed participation in the CMM. & 3.6 & 0.69 \\
\hline 20 & The CMM promoted me in understanding Math. & 3.5 & 0.72 \\
\hline 21 & The CMM promoted me in learning new strategies in solving problems. & 3.6 & 0.72 \\
\hline 22 & I'll recommend participation in the CMM to my friends. & 3.6 & 0.75 \\
\hline 23 & The tasks in the CMM were difficult. & 2.9 & 0.9 \\
\hline 24 & The tasks in the CMM were interesting. & 3.5 & 0.72 \\
\hline 25 & My motivation to learn Math increased after taking part in the CMM. & 2.9 & 1.09 \\
\hline 26 & Learning through the Internet is better that in regular class. & 2.6 & 1.17 \\
\hline
\end{tabular}

In this group of students, most of whom were not only persistent but also successful in solving challenging tasks, along with a highly positive attitude towards mathematics, we observed a high level of satisfaction with the marathon. Namely, the section of the questionnaire devoted to their perception of the CMM reveals that the majority of students enjoyed participating in the competition $(\mathrm{M}=3.6, \mathrm{SD}=0.69, \mathrm{~N}=51)$, found the tasks interesting $(\mathrm{M}=3.5, \mathrm{SD}=0.72, \mathrm{~N}=51)$ and would recommend it to their friends $(\mathrm{M}=3.6, \mathrm{SD}=0.75, \mathrm{~N}=51)$.

Opinions were more divided on items regarding perception of tasks as being difficult $(\mathrm{M}=2.9, \mathrm{SD}=1.09$, $\mathrm{N}=51$ ). Also, participants showed rather divergent opinions on whether their motivation to learn mathematics increased after the marathon $(\mathrm{M}=2.9, \mathrm{SD}=1.09, \mathrm{~N}=51)$ and whether the Internet form of competition was better than regular learning in the classroom $(\mathrm{M}=2.6, \mathrm{SD}=1.17, \mathrm{~N}=51)$.

Surprisingly, as follows from both questionnaires, there seems to be no particularly visible effect of the computer environment -an interesting finding in and of itself. Although we have no data following the face-to-face round, we can suggest that students were more focused on the mathematical tasks than on the computer environment. However, below we discuss an example from the electronic forum which illustrates the potential of Web 2.0 tools to enrich students' mathematical experiences that allow them, among other things, to communicate with others. 
It is plausible to interpret these results with the explanation given by Karadag and McDouglas (2009) who argue that 'current mathematics contests consist of single-and-absolute result problems, which may be relevant for a paper-and-pencil medium. However, we may have more opportunities using the integration of technology such as open-ended problems and problem posing. These opportunities may help students to explore mathematics more deeply and develop their own solutions. As a result of this exploration, they may discover the beauty of mathematics and develop an ever-growing interest in mathematics.

At the end of the second round of the questionnaire, we asked three open questions: What factors influenced you to keep going in such along competition? What did you like about the CMM? What did you dislike about the CMM?

On the first questions, the most frequently expressed option was that "a desire to win" kept them active in the competition (24 students). The next most popular reason was love of math (24). A few other individual opinions were 'I wished to prove to myself that I'm able to do that', 'I wished to prove to my friends that it's okay to be a geek'. One student said 'Because the tasks were interesting'.

On the second question, about what they liked most, 25 students mentioned 'Difficult and challenging tasks, tasks that required deep thinking'. A much smaller number of students (8) said that they liked the tasks they solved successfully or the task completion itself (4), 'The pressure I felt when checking the results', 'The results (place) that I achieved in the Marathon', 'That I was one of the first 50 students' (invited to the final stage). As solely mentioned factors we found 'New strategies in solving problems', 'The questions that made me confused', 'The marathon forced me to make an effort when solving problems', 'That it was virtual'; 'The possibility of asking questions in the Forum'. One student said that there was nothing special he/she liked and another said he/she liked everything. The last answer conforms with another 10 students who answered the 3rd question: 'What did you dislike in the CMM?' with the answer, 'I liked everything'.

However, the most prevalent was the opinion (shared by 19 students) that some questions were too difficult ('The problems were much too challenging for me'; 'I did not like the questions that took a lot of time to solve; 'I am not very successful'; 'I did not like the tricky questions'), compared to five students who said they did not like the questions that were easy to solve. Six students seemed to dislike 'The time I needed to wait until getting the next tasks' (one week) and 'The small number of tasks published per week' (4). Sole opinions mentioned that 'I did not like the fact that kids' scores were published on the site' and that 'Once I forgot to send in my solutions'.

Examples of Problems

As presented above, most of the problems in the CMM were aimed at the types of challenges that do not appear in the regular classroom: logic problems and problems using common sense, inquiry-based problems and non-standard problems.

Students' successes and difficulties with particular tasks

The following example shows that taken out of the 'traditional' academic context, logic and common sense problems may pose substantial difficulties to students. In solving the following problem not one of the 96 students who attempted it was successful.

(Round 6):

Noa had 6 candies and Adi had 3 candies and Lital had no candies at all. Noa, Adi and Lital shared all the candies they had. The next day Lital gave Adi and Noa 3 bubble gums and asked to divide them between them in a fair way (in return for their having shared their candies). How many bubble gums should Adi receive as his fair share? 
Results according to the given answers were: a. $0 \%$ (correct answer), b. $36 \%$, c. $18 \%$, and d. $10 \%$. Another $36 \%$ of the participants (that opened this question) did not submit any answer at all.

It seems that the concept of "fair sharing" perceived by students in real life is different from the one interpreted in a more mathematical way. Most of the submitted answers (36\%) considered the same proportion that existed in the number of candies that Noa and Adi had before sharing 6:3. According to the same proportion, just as they divided 3 bubble gums - 2:1, Adi should get 1 bubble gum. $18 \%$ of the students that chose answer ' $c$ ' (2 bubble gums) probably confused Adi with Noa but still used the same proportion - 1:2. The correct answer was 'a' (0 bubble gums), because Adi did not share his candies with anybody. He had 3 candies before sharing and he stayed with 3 candies after sharing. Therefore, only Noa shared her candies with Lital, and she should get all the bubble gums! It is plausible to suggest that this problem might pose a challenge to people's intuitive perception of sharing, and perhaps this was the reason for their difficulty in solving it correctly.

At the same time, the following problem, also featuring logic and common sense, had much more success $(\mathrm{N}=58$, Round 11$)$.

With money that Noa has she can buy 8 candies and 7 ice creams or 5 candies and 8 ice creams. Noa decided to buy only candies with all the money she had. How many candies can she buy with the money she has?
15
b. 21
c. 24
d. 29

Results according to the given answers were: a. $2 \%$, b. $9 \%$, c. $2 \%$, d. $78 \%$ (correct answer). Another $9 \%$ of the participants (that opened this question) did not submit any answer at all.

This task does not appear in the 5th grade text book and belongs to common sense and pre-algebra topics. Based on some in-school experiences, students could use diagrams with weights to solve such problems:

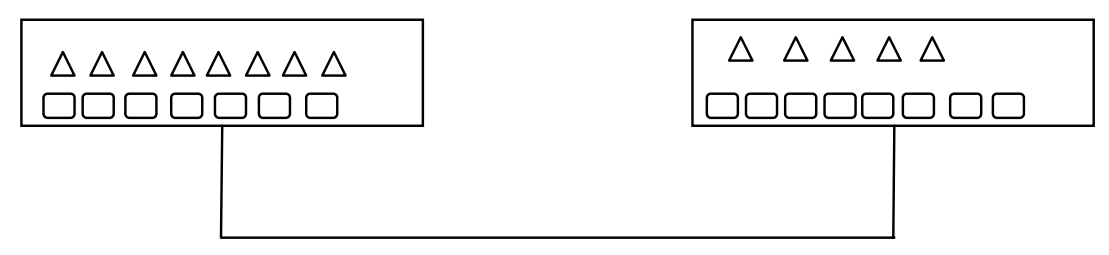

Then students take out the same elements from both sides and get:

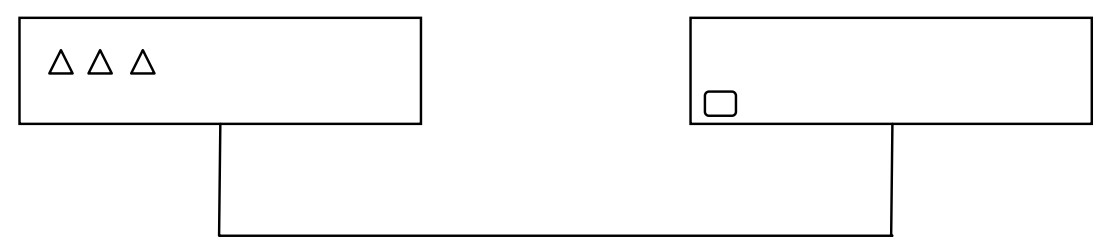

Then 1 ice cream "weighs" the same as 3 candies. 7 ice creams are equivalent to 21 candies and there are 8 more, so the correct answer is: d. 29 candies.

It may be less surprising that students had more success with the following problem taken from the Israeli curriculum for the 5thgrade ( $\mathrm{N}=67$, Round 10): 
Noam bought $\frac{3}{4}$ liters of milk in bottles $\frac{1}{8}$ liters each. How many bottles of milk did Noam buy?

b. 5

c. 6

d. 8

Results according to the given answers were: a. $9 \%$, b. $4 \%$, c. $78 \%$ (correct answer), and d. $3 \%$. Another $16 \%$ of the participants (that opened this question) did not submit any answer at all.

Authors' comments: It is important to note that in the 5thgrade, students still have not learnt division of fractions but they should know how to bring fractions to a common denominator using equivalent fraction extensions; therefore, after using the equality $\frac{3}{4}=\frac{6}{8}$ they could conclude that six times $\frac{1}{8}$ equals $\frac{6}{8}$.

Not surprisingly, students were less successful with non-routine problems that go beyond the scope of the school curriculum and require more sophisticated mathematical reasoning, like the following one (N=96, Round 6):

How many zeros are in the end of the product of $20 \times 21 \times 22 \times \ldots \times 59 \times 60$ ?
5
b. 9
c. 10
d. 11

Results according to the given answers were: a. $27 \%$, b. $27 \%$, c. $18 \%$, and d. $17 \%$ (correct answer). Another $11 \%$ of the participants (that opened this question) did not submit any answer at all.

Namely, $27 \%$ of the 96 participants who chose answer a. assumed that only numbers that have the last digit of zero give a zero at the end of the product (numbers like 20,30,40,50 and 60). Another $27 \%$ of the participants chose option $b$. perhaps because they supposed that numbers that have the last digit of zero or 5 could create zero at the end of the product (numbers 20,30,40,50,60 and 25,35,45,55). Another $18 \%$ of the participants who chose option c. Probably found that 25 (or 50) could give two zeros in the end-product. Finally, only $17 \%$ of students who attempted to solve this problem marked the number 11 (answer d.) as correct.

\section{Example from the discussion forum}

In a discussion forum placed on the CMM site, participants (students) could ask questions to which pre-service teachers and tutors could provide them with clarifications and, if necessary, some hints. Every participant was entitled to ask questions. However, pre-service teachers and tutors were not available all the time, so other participants started to answer their peers' questions, as illustrated in the following problem $(\mathrm{N}=373$, Round 1$)$ :

In a certain store you can buy one pencil for 5 shekels or 3 pencils of the same type for 10 shekels. In both cases the vendor makes the same profit. What is the profit?
1
b. 1.5
c. 2
d. 2.5

Results according to the given answers were: a. $2 \%$, b. $14 \%$, c. $9 \%$, d. $53 \%$ (correct answer). Another $22 \%$ of the participants (that opened this question) did not submit any answer at all.

This is a typical word problem for 8thgraders who are normally taught to use two equations with two unknowns. Namely, by putting the original cost of one pencil (before the profit) at $x$-value and the amount of profit at $y$-value, one could write $x+y=5$ and $3 x+y=10$; from this we get $2 x=5$ and $x=2.5 ; y=2.5$. In 5thgrade, since students have not yet learnt algebra, they would probably proceed in a different manner, like drawing a diagram or using a guess and check strategy. In all cases, they would need to demonstrate a good understanding of the problem, devise a plan, describe the problem 
mathematically and solve it, and, finally, verify their solution (similar to Polya's model for problemsolving). In this case, the problem is more challenging, which is demonstrated in its statistics.

This problem appeared in the very first set, so all 373 students who began the competition had at least opened the file with the task, and 291 of them submitted answers.

We see that only $53 \%$ of the participants gave a correct answer. Not surprisingly, the discussion forum was used by some participants for clarification. Here is an excerpt from the discussion:

Student 1: I don't understand how the seller can get the same profit in both cases.

Student 2: Me neither. I also did not understand how it could happen until I got 1000 explanations! Here is the explanation of my aunt:

If the original price of the pencil was 1 shekel, then the profits were 4 shekels and 7 shekels respectively (in cases of selling 1 pencil and 3 pencils).

If the original price of the pencil was 2 shekels, then the profits were 3 shekels and 4 shekels respectively (in cases of selling 1 pencil and 3 pencils).

If the original price of the pencil was 3 shekels, then the profits were 2 shekels and 1 shekel respectively (in cases of selling 1 pencil and 3 pencils).

Then we need some value between 2 shekels and 3 shekels. Let's try 2.5 shekels.

If the original price of the pencil was 2.5 shekels then the profits were 2.5 shekels and 2.5 shekels respectively (in cases of selling one pencil and 3 pencils).

Student 1: Thanks for the help!

Student 3: The way you presented here is not correct! If the profit was 1,000,000 shekels, what could you do with this strategy?! If you want, send me your email via the Forum and I'll send you the detailed and correct solution.

Student 4: I want to answer your question. If you divide 10 by 3 you get 3 and one third. Then you should think about getting the same profit in the second case.

Student 5: I still don't understand.

Student 3: If you simply think well and go inside of the task, then you will understand. It is really an easy task! Take a pen and notebook and do your calculations. In this way it will be much easier to find the answer.

Student 6: I did not understand this question. I asked my friend from the 12thgrade. He also did not understand it and said that it could not be solved.

Student 7: Why did he think it could not be solved?

Of 9 inputs (from 7 students) quoted in the excerpt, 5 were questions related to difficulties in understanding the problem; 1 consisted of a detailed explanation given by a non-participant (the aunt of a student); 1 was a reaction with thanks for the explanation; 1 claimed to be able to improve the solution; and 1 was a general suggestion of a strategy that helps in understanding the problem and its solution.

We were not surprised by many of the questions related to the understanding of the problem. It was a very predictable question, and that was one of our reasons for choosing this task. The text contains a kind of contradiction based on the property of proportions: intuitively, the profit of selling three pencils should be three times more than the profit of selling one pencil.

More interestingly, a correct solution based on the "trial and error" method and appropriate to a $5^{\text {th }}$ grade level of understanding came from a student who expressed a very emotional reaction, exhibiting frustration before receiving assistance from an adult ("I also did not understand ... until I got 1000 explanations"). By sharing this explanation with other participants online (where all of them could see it), this student apparently 'forgot' that this was actually a competition, thereby giving greater chances to his rivals. 
The third student criticised, to a certain degree, the disadvantages of the trial and error strategy and claimed to have a more general solution and a more efficient strategy which she was ready to share by e-mail, also quite a generous suggestion for a competitor. It appears that a group of participants, when working in an appropriate "virtual environment " (like having the use of a discussion forum), could act more as a community of learners (Renninger and Shumar, 2002) and less as individual competitors, a claim to be studied in-depth in future stages of this project.

\section{Conclusion}

Following recent trends of looking more closely at the pedagogical value of a mathematics competition that extends its reach beyond the 'traditional goal' of seeking and nurturing mathematical talent, we aimed towards widening and extending enrichment opportunities for all students regardless of gender or ability-related issues (Applebaum et al, 2012; Lam, 2012). By looking at the way to do so (our first question), this paper describes a new local initiative to invite all Grade 5 students from one municipality to take part in a "virtual" (online) part of a mathematical marathon which concluded with a face-to-face round to which the top 50 achievers in the online part were personally invited. We first described the dynamics of the online participation data which confirm trends we discovered in our previous projects of this type (Freiman and Applebaum, 2011): many participants in the first round (373), and significantly fewer in the last one (58), with a total of 480 participants. Despite these fluctuations which are difficult to interpret (too many factors can affect the participation over a long period of time), we again observe a group of students who we claim belong to the "mathematically promising" in terms of Sheffield's (1999) definition, enriched further by Leikin (2009), by introducing the abilities-motivations-beliefs- opportunities cycle to increase our understanding of how this definition works in practice.

Related to the second question, our findings come from two questionnaires, one about participants' motivation and attitudes towards mathematics, administered at the beginning of the competition (with 235 respondents), and another one about the perceptions of the experience for those who persevered (51 responses), at its end. Not surprisingly, from the first questionnaire we learn that mathematics is generally well perceived by the respondents; they seem to devote efforts to learning it well and doing it successfully. Moreover, taking part in the competition seems to be positively perceived by students who stayed till the end, which can also be explained by their high motivation (both intrinsically - the joy of solving interesting problems, and extrinsically - the possibility of winning a prize: an elaborate puzzle or a strategy game). However, our data set has several limitations, the major one being that we did not see students' reasoning behind their multiple-choice answers; we may need to look for different forms of submitting solutions that provide students (and researchers) with an opportunity to share their way of thinking, as also suggested by Lam's (2012) research. We should also explore the potential of working in teams and of bridging the gap between mathematics as 'fun' (by organising competitions) and the everyday classroom experience. The latter can thus be enriched with non-routine problems, as suggested by Bicknell and Riley (2012) who also advocate making competitions part of mathematical curricula in schools.

We identified a small group of students (approximately 10\%) who participated in the marathon but claimed that they generally do not like (or enjoy) mathematics. It would be interesting to learn more about their reasons for saying so. The fact that they participated in the competition despite their attitude makes us ask further questions about this phenomenon and continue investigating this finding, also in light of recent research on mathematical giftedness and creativity showing that some highly creative students may be underachievers in traditional classrooms (Kim, 2008). We do not know whether this small group of students are gifted or not and how well they do in the regular 
curriculum but, potentially, mathematics competitions can give them an alternative opportunity to show their talents and realize their high potential (Weinberg et al., 2011).

Another interesting finding was to learn that technology does not seem to have a significant impact on students' everyday experiences; the responses regarding their perceptions and use of virtual environments were split, thus showing students who seem to enjoy spending a lot of time with technology while others enjoy it a bit less. More research is needed to explain this finding. One of the promising paths is to look at the discussion on the electronic forum (a new idea for the 'virtual marathon' we had not explored before) which showed us that students tended to share their solutions and help each other. We saw that some of them could explain solutions and encourage other students to solve problems.

Our future work will use more data and look at more detailed data analysis including interviews that could reveal the reasons for the students' behaviour and insightful comments about their thoughts and attitudes during this online problem solving activity. Also interviews with in-service teachers can help us to better understand whether or not participation in the CMM influenced their class mathematical activity and students' behaviour in math lessons and their achievements.

Furthermore, a more detailed analysis is needed regarding the tasks used in our competition and students' successes with certain ones versus their difficulties with others. For example, in some problems that involved riddles, students tried to make judgments based on their 'intuition' in a 'reallife' context and not necessarily by looking at mathematical relationships. The examples analysed in the current paper do not provide enough evidence to draw conclusions, but it seems that generally the problems that were closer to familiar models used in the regular classroom (even if more complex) were more successful than ones that were more non-standard, requiring unusual thinking and generalisations.

\section{References}

Applebaum, M., Kondratieva, M., \& Freiman, V. (2012). Gender-related Issues in Mathematical Competitions: Participation in the Virtual Mathematical Marathon. Proceedings of the International Congress on Mathematics Education (ICME-12), Seoul, South Korea.

Barbeau, E., \& Taylor, P. (Eds.) (2009). Challenging mathematics in and beyond the classroom. The 16th ICMI Study: New ICMI Study Series, Springer.

Bicknell, B., \& Riley, T. (2012). The role of competitions in a mathematics programme. APEX: The New Zealand Journal of Gifted Education, 17 (1). www.giftedchildren.org.nz/apex. (accessed August 2013)

Berzina, I., Bonka, D., \& Lace, G. (2007). The mathematical content of junior contests: Latvian approach. Mathematics Competition, 20(1), pp. 25-35.

Freiman, V., \& Applebaum, M. (2011). Online Mathematical Competition: Using Virtual Marathon to Challenge Promising Students and to Develop Their Persistence. Canadian Journal of Science, Mathematics and Technology Education, 11(1), pp. 55-66. Guzman, M. (1990). The role of games and puzzles in the popularization of mathematics. L'Enseignement Mathématique 36, pp. 359-368.

Karadag, Z., \& McDougall, D. (2009). E-contests in mathematics: Technological challenges versus technological innovations. Revista de InformaticaAplicada/Journal of Applied Computing, 1, pp. 21-27.

Kenderov, P.S. (2006). Competitions and mathematics education. In M. Sanz-Sole, J. Soria, J. L. Varona, \& J. Verdera (Eds.), Proceedings of the International Congress of Mathematics, Madrid 2006 (pp. 1583-1598). European Mathematical Society: Madrid, Spain. http://www.icm2006.org/proceedings/Vol_III/contents/ICM_Vol_3_76.pdf (accessed August 2013)

Kenderov, P., Rejali, A., Bartolini-Bussi, M. G., Pandelieva, V., Richter, K., Mschietto, M., Kadijevich, D., \& Taylor, P. (2009). Challenges Beyond the Classroom - Sources and Organizational Issues. In: Barbeau E. \& Taylor P. (Eds.) (2009). Challenging mathematics in and beyond the classroom. The 16th ICMI Study: New ICMI Study Series, Springer, pp. 53-96.

Kim, K. (2008). Underachievement and Creativity: Are Gifted Underachievers Highly Creative? Creativity Research Journal, 20(2), pp. 234-242.

Koichu, B., \& Andzans, A. (2009). Mathematical Creativity and Giftedness in Out-of-school Activities. In: R. Leikin, A. Berman, and B. Koichu (Eds.) Creativity in Mathematics and the Education of Gifted Students. Sense Publishers, pp. 285-308.

Lam, T. (2012). The Roles of Mathematics Competition in Singapore Mathematics Education. Proceedings of the International Congress on Mathematics Education (ICME-12), Seoul, South Korea. 
Leikin, R. (2009). Bridging Research and Theory in Mathematics Education with Research and Theory in Creativity and Giftedness. In: R. Leikin, A. Berman, and B. Koichu (Eds.) Creativity in Mathematics and the Education of Gifted Students. Sense Publishers, pp. 385-411.

Polya, G. (1973). How to solve it. NJ: Princeton University Press.

Regato, J. C. (1982). Organize a Math Games Tournament! In: Mathematics for the middle grades (5 - 9). Yearbook; 1982. National Council of Teachers of Mathematics, pp. 226 -231.

Renninger, K. A., \& Shumar, W. (Eds.) (2002). Building Virtual Communities: Learning and Change in Cyberspace. Cambridge University Press.

Rosolini, G. (2011). The Italian Team Competition. Mathematics Competitions, 24 (2), pp. 14-22.

Schneider, J. (1994). Issues for the popularization of mathematics. In Proceedings of the International Congress of Mathematicians, Zürich, Switzerland.

Simpkins, S. D., Davis-Kean, P. E., \& Eccles, J. S. (2006). Math and Science Motivation: A Longitudinal Examination of the Links between Choices and Beliefs. Developmental Psychology, 42(1), pp. 70-83.

Sheffield, L. J. (Ed.) (1999). Developing Mathematically Promising Students. Reston, VA: National Council of Teachers of Mathematics.

Soifer, A. (2010). A Quarter of a Century Discovering and Inspiring Young Gifted Mathematicians: All the Best from the Colorado Mathematical Olympiad. Mathematics Competitions, 23 (1), pp. 39-50.

Soifer, A. (2012), The Goal of Mathematics Education, including Competitions, is to let Student touch "Real" Mathematics: We Ought to Build that Bridge. Mathematics Competitions, 25(2), pp. 47-67.

Weinberg, A. E., Basile, C. G., \& Albright, L. (2011).The Effect of an Experiential Learning Program on Middle School Students' Motivation toward Mathematics and Science. Research in Middle Level Education, 35(3), pp. 1-12. 